\section{Human rights in Cuba}

SIR - C. J. Brown and I have compiled a directory of 63 cases of Cuban political dissidents abused by psychiatric methods ${ }^{1}$. Thirty-one of these cases could be documented from the publications of Amnesty International and Americas Watch, and revealed a systematic pattern of abuse and torture. Eleven dissidents were forcibly subjected to electroconvulsive therapy, 16 were forcibly given high doses of psychotropic drugs, most chlorpromazine, and four were interned with criminally insane patients in the Havana Psychiatric Hospital, and there threatened with electroshocks to frighten them and secure confessions of political offences.

The political nature of the dissidents' offences cannot be doubted. Eight were interned after unsuccessful attempts to leave Cuba illegally; another ten were interned for unspecified counterrevolutionary activities; eight were accused of writing anti-Castro graffiti and distributing human rights leaflets; and the rest were accused of various offences, including contempt for the regime, refusal to serve in the Cuban armed forces and alleged participation in plots to kill Fidel Castro. The age of the dissidents ranged from 16 to 61 . A variety of occupations and professions were represented but two groups stood out: students and journalists (5) and writers (6).

Most of the abuses took place in the forensic wards of the Havana Psychiatric Hospital, the Gustavo Machín Hospital in Santiago de Cuba and the Combinado del Este Prison Hospital in a suburb of Havana. The forensic wards of these hospitals are under the direct control of the Cuban Department of State Security, the Cuban KGB. The duration of confinement varied from three days to five years in the cases of two dissidents. Cuban penal law allows for placing prisoners for up to a month at the Havana Psychiatric Hospital for psychiatric evaluation. But in more than half the cases analysed, the period of internment exceeded a month, in four cases was longer than a year. Only 11 of the cases investigated were diagnosed by Cuban authorities as suffering from mental illnesses. Three dissidents never received a psychiatric evaluation, and four others were diagnosed as sane but were nevertheless sent back to the psychiatric wards for further confinement. One dissident was diagnosed as "apathetic to socialism" and another as suffering from "delusions of being a defender of human rights".

None of the Cuban dissidents was diagnosed as suffering from sluggish schizophrenia, the diagnosis that was often used in the Soviet Union to intern dissidents in psychiatric hospitals ${ }^{2}$.

Although electroconvulsive therapy is appropriate for some mental illnesses, such as severe depression and catatonic schizophrenia, this therapy is systematically applied in Cuba to punish past dissident actions. Electroshocks are applied without medical supervision and under barbaric conditions. The dissidents were not given muscle relaxants to prevent fractures and, while forcibly held to the floor by criminal orderlies, their bodies were doused with water to increase electrical conductivity and electroshocks administered on floors covered with vomit, urine and excrement.

In the case of the 61-year-old businessman Eugenio de Sosa, who received 14 electroshock sessions as punishment for smuggling messages from prison, most of the electroshocks were applied to his testicles. Another dissident, the truck driver José Morales, received one of his 14 electroshocks while submerged in a water tank used for cattle. Jesús Leyva, a union leader, received 24 electroshock sessions. In an interview broadcast on television in Florida, Leyva claimed that after one electroshock session he did not recognize his wife or his relatives. Roberto Bahamonde, an agricultural engineer, underwent eight electroshock sessions after writing Fidel Castro a private letter suggesting that material incentives be instituted to increase production. He told journalist George Gedda of Associated Press that it took him years to recover his memory.

Equally disturbing were the large doses of psychotropic drugs that dissidents are forced to ingest. A major problem with these drugs is their side effects. One such side effect interferes with the extrapyramidal functions of the brain responsible for movement, locomotion and coordination. The danger of becoming a human vegetable by experiencing a chemical lobotomy from long-term exposure to drugs is $\mathrm{real}^{3}$. Several of the Soviet victims of psychiatric abuse exhibited these side effects ${ }^{3}$, as did one of our cases.

The time has come to insist that these practices be stopped by the Cuban government. Political use of psychiatry in Cuba must end.

ARMANDO J. LAGO

Of Human Rights,

Box 2160, Hoya Station,

Georgetown University,

Washington, DC 20057, USA

1. Brown, C. J. \& Lago, A. M. The Politics of Psychiatry in Revolutionary Cuba. (Transaction Books, New Brunswick, New Jersey, 1991)

2. Firestone, H. Soviet Psychoprisons (Norton, New York 1979).

Bloch, S. \& Reddaway, P. Psychiatric Terror (Basic Books, New York, 1977)

\section{In situ situation}

SIR - In a recent issue of Nature $\mathbf{3 5 5}$, $163 ; 1992)$, we were attracted by the title of a paper, "Rapid-time-course miniature and evoked excitatory currents at cerebellar synapses in situ", especially as we were looking forward to welcoming new members to the otherwise evershrinking club of people performing intracellular recordings in whole animals. But our surprise and disappointment were great when we read the paper and discovered that the work had been done in vitro, in a slice. We do not have any qualms about the quality of this work, but we do feel that the use of the term 'in situ' was clearly misleading in this case. Indeed, it is difficult to see why it was added to the title.

We should like to suggest that 'in situ' should not used to refer to work done in vitro, as there are already precedents in the literature - for example: Do et al. Neuroscience 8, 2226 (1986) Herreras, J. Neurophysiol. 64, 1429 (1990); Herrling et al. Neuroscience 31, 213 (1989); Hernandez et al. Expl Brain Res. 85, 66 (1991) - where this term is used to refer to work carried out in whole animals. We suggest following the practice of the Journal of Physiology where work carried out in brain slices or cultures is referred to as 'in vitro'. Work done on whole organisms should be termed 'in vivo' or 'in situ'.

\section{c/o Sandoz Research \\ Institute Berne Ltd, $\mathrm{CH}-3001$ Berne,}

Switzerland

Paul L. Herrling

Department of Visual Science

Institute of Ophthalmology,

Judd Street, London WC1H 9QS, UK

\section{Speaking volumes}

SIR - VCH, the publishers of the European Journal of Immunology, point out that, contrary to my statement (Nature 354, 346; 1991), their journal cover does indeed display the volume number. I acknowledge my error, but the volume number is in small type at the foot of the page among a plethora of other data, whereas the issue number is presented at the head of the page, in the same large typeface as the journal title and year.

The fact that I, an experienced professional librarian, can make such a mistake only goes to strengthen the case for some sort of standardization of bibliographic data.

MRC Human Genetics Unit,

SHEILA M. MOULD

Western General Hospital,

Crewe Road,

Edinburgh, EH4 2XU, UK 